A Pharm-Ecological Perspective of Terrestrial and Aquatic Plant-Herbivore Interactions

Jennifer Sorensen Forbey, M. Denise Dearing, Elisabeth M. Gross, Colin M. Orians, Erik E. Sotka \& William J. Foley

Journal of Chemical Ecology

ISSN 0098-0331

Volume 39

Number 4

J Chem Ecol (2013) 39:465-480

DOI 10.1007/s10886-013-0267-2
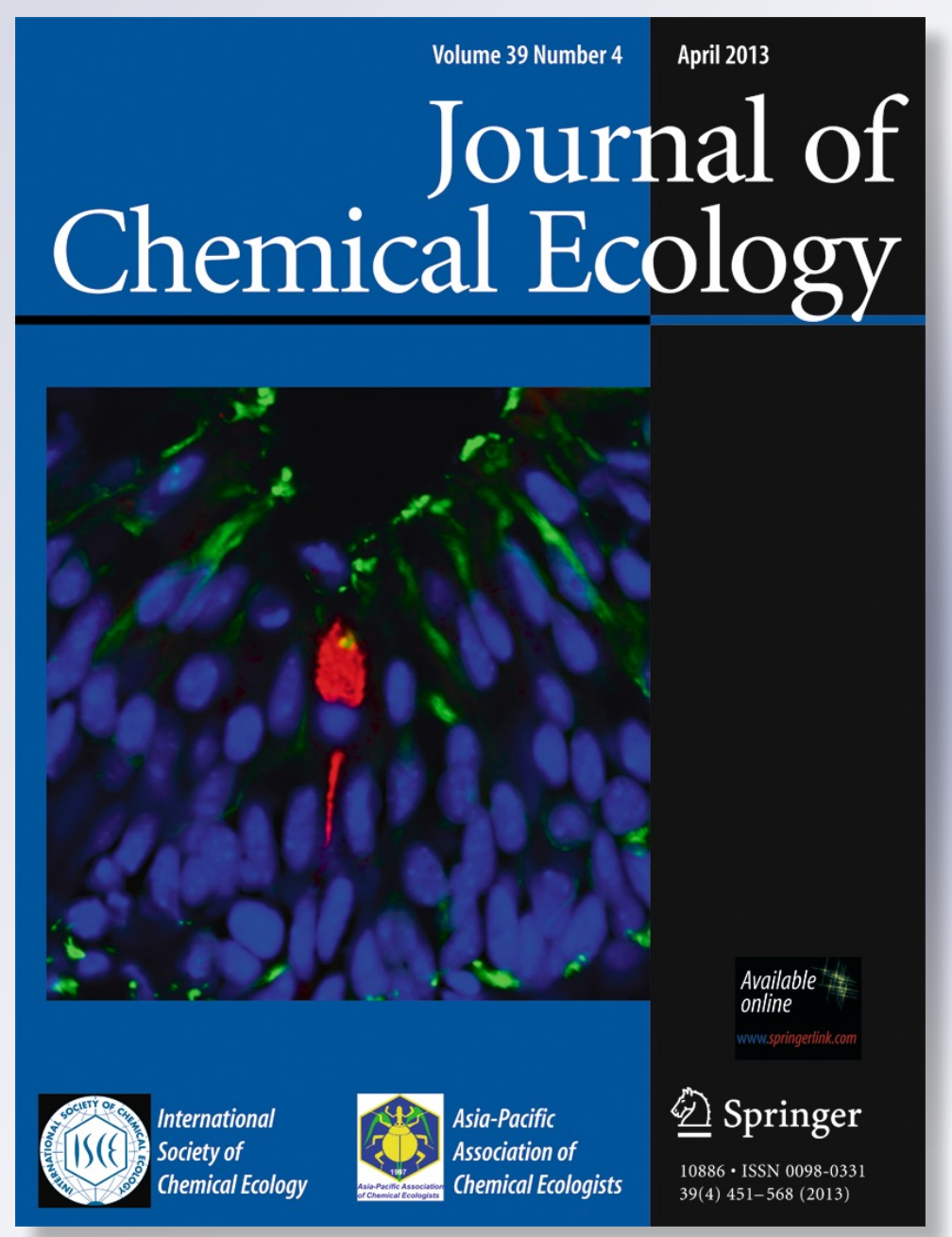

脰 Springer 
Your article is protected by copyright and all rights are held exclusively by Springer Science +Business Media New York. This e-offprint is for personal use only and shall not be selfarchived in electronic repositories. If you wish to self-archive your article, please use the accepted manuscript version for posting on your own website. You may further deposit the accepted manuscript version in any repository, provided it is only made publicly available 12 months after official publication or later and provided acknowledgement is given to the original source of publication and a link is inserted to the published article on Springer's website. The link must be accompanied by the following text: "The final publication is available at link.springer.com". 


\title{
A Pharm-Ecological Perspective of Terrestrial and Aquatic Plant-Herbivore Interactions
}

\author{
Jennifer Sorensen Forbey • M. Denise Dearing • \\ Elisabeth M. Gross • Colin M. Orians • Erik E. Sotka • \\ William J. Foley
}

Received: 7 October 2012 /Revised: 5 February 2013 / Accepted: 19 February 2013 /Published online: 13 March 2013

(C) Springer Science+Business Media New York 2013

\begin{abstract}
We describe some recent themes in the nutritional and chemical ecology of herbivores and the importance of a broad pharmacological view of plant nutrients and chemical defenses that we integrate as "Pharm-ecology". The central role that dose, concentration, and response to plant components (nutrients and secondary metabolites) play in herbivore foraging behavior argues for broader application of approaches derived from pharmacology to both terrestrial and aquatic plant-herbivore systems. We describe how concepts of pharmacokinetics and pharmacodynamics are used to better understand the foraging phenotype of herbivores relative to nutrient and secondary metabolites in food. Implementing these concepts into the field remains a challenge, but new modeling approaches that emphasize
\end{abstract}

J. S. Forbey $(\bowtie)$

Department of Biological Sciences, Boise State University, Boise,

ID 83715-1515, USA

e-mail: Jenniferforbey@boisestate.edu

M. D. Dearing

Department of Biology, University of Utah,

Salt Lake City, UT 84103, USA

E. M. Gross

Université de Lorraine, Laboratoire Interdiciplinaire

Environnements Continentaux (LIEC) CNRS

UMR 7360, Campus Bridoux,

57070 Metz, France

C. M. Orians

Department of Biology, Tufts University,

Medford, MA 02155, USA

E. E. Sotka

Department of Biology, College of Charleston,

Charleston, SC 29412, USA

W. J. Foley

Research School of Biology, Australian National University,

Canberra 0200, Australia tradeoffs and the properties of individual animals show promise. Throughout, we highlight similarities and differences between the historic and future applications of pharmecological concepts in understanding the ecology and evolution of terrestrial and aquatic interactions between herbivores and plants. We offer several pharm-ecology related questions and hypotheses that could strengthen our understanding of the nutritional and chemical factors that modulate foraging behavior of herbivores across terrestrial and aquatic systems.

Keywords Aquatic $\cdot$ Herbivore $\cdot$ Nutrient $\cdot$ Pharmacology Plant secondary metabolite $\cdot$ Terrestrial $\cdot$ NIRS $\cdot$ Foraging

\section{Introduction}

For several decades now, a central focus in the field of nutritional ecology has been to understand the factors that influence the foraging behavior of terrestrial and aquatic herbivores (Scriber and Slansky, 1981; Choat and Clements, 1998; Foley et al., 1999; Dearing et al., 2005; Clements et al., 2009; Raubenheimer et al., 2009). There is ample evidence from each of these areas that the foraging behavior of herbivores is driven by both nutrients and chemical defenses. Variation in macro- and micronutrients (e.g., protein, carbohydrates, sodium) in foods coupled with the nutritional requirements of herbivores influence intake and food preference (Raubenheimer and Simpson, 1997; Barboza et al., 2009; Behmer, 2009; Clements et al., 2009). However, the presence of plant secondary (or specialized) metabolites (PSMs), which can act as chemical defenses, often constrain intake despite the abundance of critical nutrients in those foods (Hay and Fenical, 1988; Palo and Robbins, 1991; Appel, 1993; Foley and McArthur, 1994; Behmer et al., 2002; Dearing et al., 2005; Paul et al., 2006; Raubenheimer and Simpson, 2009). 
Although both nutrients and secondary metabolites influence foraging behavior, there is a general lack of ability to $a$ priori predict diet selection even when the nutritional and chemical profiles of available plants are well documented (Kool, 1992; Yeager et al., 1997; Cruz-Rivera and Hay, 2003; Clements et al., 2009; Sotka et al., 2009). Reasons for this shortcoming are that herbivores often have different nutritional intake targets, and that nutrients and PSMs are too often treated separately (reviewed in Behmer, 2009). Another reason is that researchers tend to regard nutrients as "therapeutic" components that always result in positive consequences whereas PSMs are considered "toxic" components with inevitable negative repercussions. As such, nutrients and PSMs historically have been studied independently despite proposals for a unified marriage of these components since the 1970s (for review, Horn, 1989; Slansky, 1992). However, the definition of a nutrient versus a toxin is not necessarily clear and is a function of the dose, the herbivore's homeostatic state (Raubenheimer and Simpson, 2009; Raubenheimer et al., 2009), and interactions among nutrients and toxins. In some cases, compounds widely perceived as nutrients, such as amino acids, may be feeding deterrents in their free form (DeGabriel et al., 2002; Lokvam et al., 2006; Field et al., 2009; Huang et al., 2011). In other cases, animals use PSMs in a manner consistent with them being therapeutic (see Forbey et al., 2009). Moreover, PSMs can have contrasting effects in that they may be detrimental to some herbivores in some contexts, while having positive effects elsewhere. As an example, low levels of diterpene alcohols produced by Dictyotalean seaweeds deter larger generalist fish and urchins, but are feeding stimulants to smaller amphipods and worms (Hay et al., 1987). In other examples, tannins can reduce availability of protein in food for some vertebrate herbivores (Targett and Arnold, 2001; Barbehenn and Constabel, 2011) but may also work as antihelminthics (Min et al., 2003) or as antiviral agents (Hunter and Schultz, 1993; Appel and Schultz, 1994) in other herbivores.

Given that PSMs and nutrients occur simultaneously in food, there is much to be gained from approaches that investigate the mechanisms by which both nutrients and PSMs act individually and together to influence the foraging ecology, or foraging phenotype, of herbivores. Numerous studies have investigated the relative "value" of these factors (Bernays et al., 1994; Simpson and Raubenheimer, 2001; Behmer et al., 2002; Behmer, 2009). In some cases, nutrients are more important than PSMs (Duffy and Paul, 1992; Cruz-Rivera and Hay, 2003; Felton et al., 2009; Van Alstyne et al., 2009), in others, PSMs are more important (Dearing et al., 2000; Erhard et al., 2007), and in still other cases, these factors are equally important or act synergistically to influence foraging behavior (Duffy and Paul, 1992; Frye et al., 2013; Simpson and Raubenheimer, 2001). While approaches, such as the geometric framework, have helped researchers study how herbivores regulate nutrient needs in variable nutritional and PSM environments (Behmer, 2009), what remains poorly understood is why certain species respond to specific thresholds of PSMs or nutrients and others do not. If we want to explain and predict variable foraging behavior of herbivores, we need to measure mechanisms that set the tolerance and requirements for PSMs and nutrients.

We propose that the field of pharmacology should be integrated with chemical and nutritional ecology to facilitate the transitions among observations of foraging behaviors in the field relative to PSM or nutrient levels (foraging phenotypes) and pharmacological mechanisms that guide foraging patterns (pharmacokinetics-pharmacodynamics, PK-PD, Fig. 1), to ultimately predict patterns of foraging behavior. This approach, linking observation with mechanism to predict pattern, was developed for terrestrial mammals but we argue it can be applied to invertebrate and vertebrate herbivores in terrestrial and aquatic habitats. Although we recognize that not all secondary metabolites consumed by herbivores are derived from plants, we use PSMs throughout to maintain a consistent language.

Our goal is to provide examples of how and why pharmacology can advance an understanding of the interactions between plants and herbivores. Researchers focused on herbivores in one system may benefit from a richer understanding of the pharmacological mechanisms that limit or expand tolerance to nutrients and chemicals by herbivores in other systems. We begin by describing studies that integrate nutritional and chemical ecology to explain herbivore foraging patterns from different systems. We then offer practical approaches from pharmacology to answer ecological questions - termed Pharm-ecology. Pharm-ecology is the study of mechanisms that limit or expand herbivore diet breadth and are useful in predicting foraging patterns. Throughout, we highlight the nuances of using pharmacological approaches in specific systems. However, we emphasize how pharmacology can offer a common approach to address questions posed by ecologists about diet selection in both terrestrial and aquatic systems. Finally, we demonstrate how ecologists can take concepts back into a natural setting to predict foraging patterns. Our hope is to stimulate researchers to perform multi-system comparisons that use pharm-ecology to address questions related to the mechanisms influencing the foraging ecology of herbivores.

In general, the workflow of a pharm-ecological project has three interacting steps. First, the investigator should observe foraging phenotypes that can be compared to other phenotypes (Shipley et al., 2009). Examples of foraging phenotypes include dietary specialists vs. generalists, different diets in populations of the same species in different habitats, or diets of animals that shift ontogenetically or 


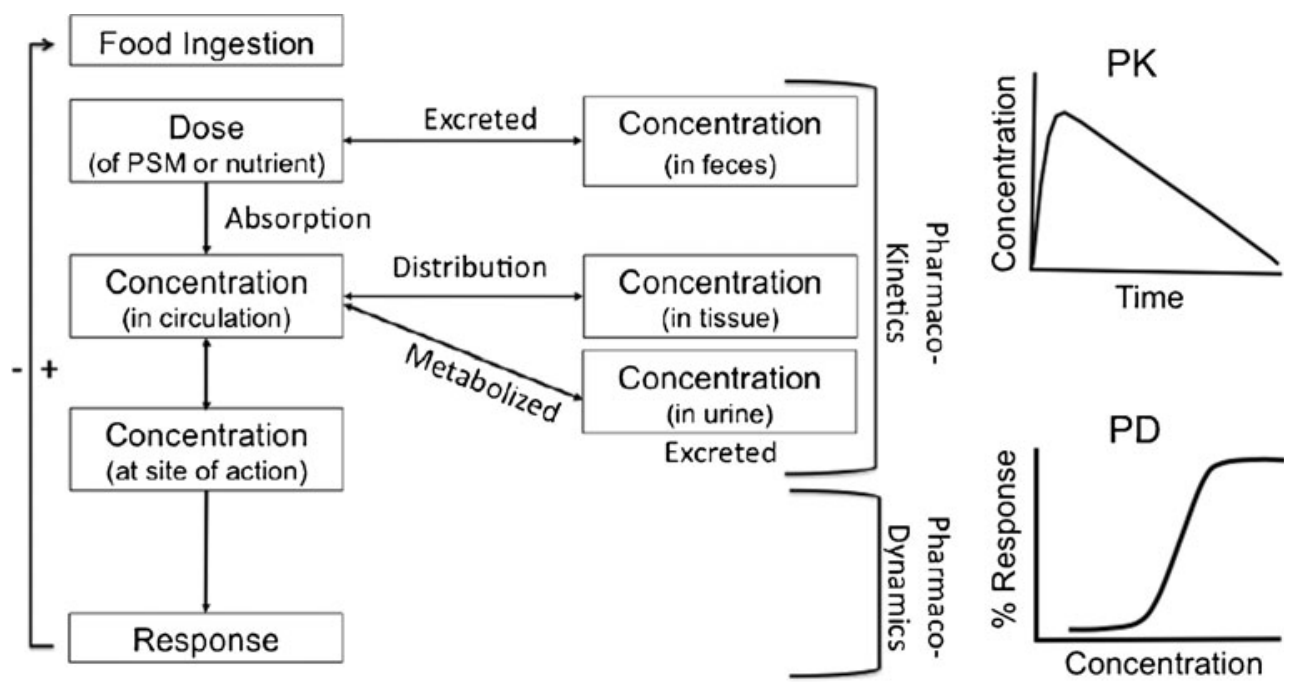

Fig. 1 Pharm-ecological concepts explaining the dose-concentrationresponse in plant-herbivore interactions. Animals consume diets containing plant secondary metabolites (PSMs) and nutrients. The doses of PSMs and nutrients ingested are dependent upon the amount of plant material ingested and concentration of these chemicals in the plant. The animal's mechanisms of absorption, distribution, metabolism, and excretion (ADME) determine the concentrations of the PSM or nutrient in body compartments (e.g., circulation, tissues) over time. The concentration-time course of chemicals is called pharmacokinetics (PK). Circulating or distributed PSMs or nutrients can interact at one or multiple sites within the body through dynamic mechanisms of action

seasonally. These comparative systems provide opportunities to understand the mechanisms that underly foraging patterns. Once foraging phenotypes have been identified, behavioral, morphological, physiological, and genetic adaptations that can influence what the body does to PSMs and nutrients (i.e., pharmacokinetics, PK) and what PSMs and nutrients can do to the body (i.e., pharmacodynamics, PD) can be compared between phenotypes. We recognize that investigating pharmacological mechanisms can be daunting. In vivo studies are recommended first to understand how the concentration of PSMs or nutrients influences intake and excretion of these substrates and their metabolites. If animals differ in intake and excretion of foodstuff, there are likely to be mechanisms driving these patterns, and more detailed pharmacokinetic and pharmacodynamic approaches such as those outlined below are warranted. We do not provide the details of such studies, but rather sketch a general overview of how these pharmacological approaches can be useful in understanding and comparing mechanisms that drive variation in foraging phenotypes.

Foraging Phenotypes: An Integrated View of Nutrients and Toxins Much of the early work on plant-herbivore interactions focused on identifying PSMs that constrained intake in herbivores. Specifically, the detoxification limitations hypothesis argued that the ability of herbivores to detoxify ingested PSMs largely determined which plants, and how in the body and elicit a physiological or behavioral response. The concentration-response relationship is called pharmacodynamics (PD). This response can directly impact the subsequent intake of food. Occasionally, the resultant metabolites of metabolism are more bioactive than the original chemical and can have pharmacodynamic responses. Herbivores may detect PSM and nutrient concentrations in the environment via volatile chemicals, after tasting the diet or perhaps in the circulation and adjust intake (dose). ADME mechanisms and sensitivity to mechanisms of action ultimately influence the response to PSMs and nutrients. But see (McLean and Duncan, 2006; Sorensen et al., 2006; Sotka et al., 2009) for additional details

much, they could eat (Freeland and Janzen, 1974; Marsh et al., 2006a). Although this hypothesis was focused largely on mammalian herbivores, the concepts apply to all herbivores. Threshold intakes of PSMs have been documented in several species of terrestrial (Govenor et al., 1997; Stapley et al., 2000; Simpson and Raubenheimer, 2001; Torregrossa et al., 2012) and aquatic (Demott, 1999; Gross and Bakker, 2012) herbivores.

There are several factors that can influence thresholds to PSMs. Nutrients may interact with PSMs to establish those thresholds. For example, common brushtail possums had higher tolerance to diets rich in benzoic acid when they were provided with substrates needed for the detoxification and excretion of benzoates (Marsh et al., 2005). In addition, supplemental energy and protein may increase the ability of herbivores to consume foods that contain diverse PSMs (Provenza et al., 2003; Nersesian et al., 2012) by providing the resources needed to pay for high energetic costs of detoxification (Foley and McArthur, 1994; Mangione et al., 2004; Sorensen et al., 2005c).

Ecological and evolutionary experience with PSMs or nutrients also plays a role in shaping foraging phenotypes. For example, previous ecological exposure to PSMs increases tolerance to those PSMs, but may decrease tolerance to novel PSMs (Gustafsson and Hansson, 2004; Sorensen et al., 2005b). Memory of the positive and negative experiences of exceeding thresholds to nutrients and PSMs via 
conditioned food aversions also can influence foraging phenotypes (Provenza et al., 1998). Animals form aversions when they associate post-ingestive illness with the taste of food. Olfactory chemoreception is the most ancient sensory cue in animals, and may be used for pre-ingestive avoidance of chemicals, whereas taste may be used for post-ingestive limitation of food intake. Although these concepts have been verified by using ecologically realistic combinations of flavors and toxins (Lawler et al., 1999), there has been some doubt cast on how well animals can generalize preferences when the foraging choices become more complex both temporally and spatially in natural systems (Ginane et al., 2005; Duncan et al., 2007; Favreau et al., 2010). However, animals can discriminate mixtures of chemicals and remember and track these olfactory cues through space and time (Derby and Sorensen, 2008). There is enormous scope for investigating the role and consequences of previous experience, learning, and associated sensory systems in understanding the foraging phenotypes of herbivores.

\section{Pharmacological Mechanisms}

It has been widely observed that the quality, quantity, and complexity of nutrients and PSMs and the learned responses to these dietary components can mediate the foraging patterns of herbivores (Hay and Fenical, 1988; Paul and Vanalstyne, 1992; Provenza et al., 1998, 2003; Simpson and Raubenheimer, 2001; Amsler, 2008; Behmer, 2009). Although the general concepts of pharmacology were introduced to ecologists to explain plant-herbivore interactions 38 years ago (Freeland and Janzen, 1974), the empirical use of pharmacology to understand mechanisms that drive foraging patterns in any system is limited (McLean and Duncan, 2006; Marsh et al., 2006b; Sorensen et al., 2006; Haley et al., 2008; Magnanou et al., 2009; Sotka et al., 2009). In contrast to the broad knowledge base that exists on the mechanisms required to process nutrients as well as on mechanisms used by domestic and laboratory species to metabolize drugs, there is a general lack of understanding of how PSMs are processed by herbivores, especially in the context of a variable nutrient environment (Appel, 1993; Karasov and Hume, 1997; Casarett et al., 2008; Gross and Bakker, 2012). The gap in knowledge related to mechanisms required to process nutrients in marine herbivorous fishes, for example, has only recently begun to close (Choat and Clements, 1998; Clements et al., 2009). Moreover, despite a long history of investigating how aquatic animals process chemical contaminants (Chambers and Yarbrough, 1976; Smital et al., 2004; Rewitz et al., 2006; Katagi, 2010), studies investigating how they process dietary secondary metabolites have only more recently been initiated (Liang et al., 2007; Richardson et al., 2009; Gross and Bakker,
2012). An understanding of pharmacology may fill these gaps in both terrestrial and aquatic systems.

The pharm-ecological approach focuses on evolutionary conserved mechanisms that define foraging phenotypes. As highlighted above, pharmacological approaches allow researchers to investigate the mechanisms that drive the fate (what the body does to a chemical, pharmacokinetics, PK) and action (what a chemical does to the body, pharmacodynamics, PD) of PSMs and nutrients in any herbivores. The pharm-ecological perspective views the foraging ecology of herbivores as a dose-concentration-response.

The general outcome of the pharm-ecological mechanisms described that minimize deficits and excesses to maintain homeostasis, is conserved across species for a range of chemicals, and therefore, can be applied to a variety of systems (see Behmer, 2009; Sotka et al., 2009). Of the parameters outlined in Fig. 1, dose (e.g., total intake), metabolism, excretion, and foraging response have received the most attention by ecologists (McLean and Duncan, 2006; Sorensen et al., 2006; Haley et al., 2008). Distribution, specifically associated with the amount and site of sequestered PSMs, is well described in terrestrial insects (Opitz and Muller, 2009; Dobler et al., 2011) and a small number of marine invertebrate systems (Pennings and Paul, 1993; Whalen et al., 2010). The mechanisms of absorption of PSMs and the resultant kinetics (i.e., time course) of secondary metabolites are known in some vertebrate (Boyle et al., 2005; Dziba et al., 2006; Mclean et al., 2007) and invertebrate herbivores (Zangerl et al., 2012). However, detailed pharmacokinetic studies where the concentrationtime profile is linked to a specific mechanisms (e.g., metabolizing enzymes, efflux transporters) are rare for all types of herbivores. Pharmacokinetic data of any kind are even scarcer for aquatic systems (Pennings and Paul, 1993; Ibelings and Havens, 2008; Martin-Creuzburg and von Elert, 2009; Whalen et al., 2010).

Pharmacokinetic Mechanisms: Dose The dose-concentration relationship is dependent primarily on the amount of substrate (nutrient or PSM) orally consumed. Other forms of substrate administration may be important, such as dosing through the skin or gills for aquatic species. Although measuring the dose consumed by an herbivore is standard practice, few researchers measure the actual systemic dose or concentration an herbivore experiences during foraging events. Both meal size and frequency influence the peak systemic concentration and exposure (area under the concentration-time curve) of substrates in the body compartment(s) (Fig. 2). For vertebrates with closed circulation systems, the most important body compartment is the blood, as it delivers the substrate to all other compartments (e.g., liver, brain, kidney). Within invertebrates, the most important compartments are the gut, hemolymph, and fat body 
(Keeley, 1985; Govenor et al., 1997). Within a species, regardless of taxonomic group or morphology, larger, more frequent doses generally result in higher concentrations of the substrate in compartments (Fig. 2).

To avoid negative consequences of PSMs, both terrestrial and aquatic herbivores must be able to detect concentrations of key PSMs and regulate intake of food accordingly. The regulation model of dose control (reviewed in Torregrossa and Dearing, 2009) proposes that herbivores regulate daily dosing through modifications to either meal size or the intervals between meals, known as the "intermeal interval". Several mammalian herbivores appear to use the strategy of altering meal size as a function of PSM concentration (Wiggins et al., 2003, 2006a, b; Boyle et al., 2005; Sorensen et al., 2005a; Marsh et al., 2007; Torregrossa et al., 2011, 2012). Of the five species studied to date (three woodrats of the genus Neotoma and two marsupials: the koala and brushtail possum), only one exhibited a change in intermeal interval when fed increasing concentration of dietary PSMs (Sorensen et al., 2005a; Torregrossa and Dearing, 2009). Recent studies suggest that generalist herbivores may be better at regulating PSM dose than specialist

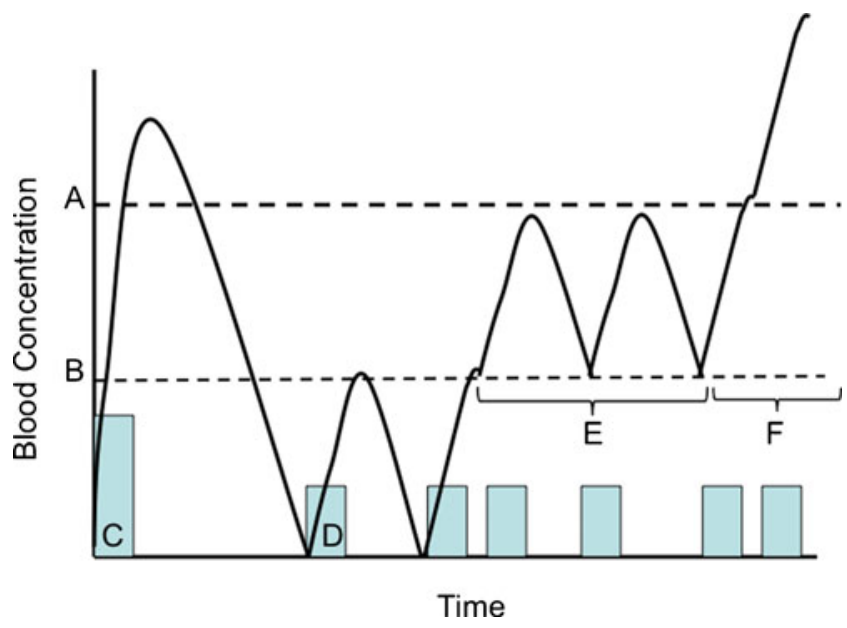

Fig. 2 A schematic of the relationship between meals (grey bars), concentration of a PSM or nutrient in the blood after a meal (solid line) and time. The upper dashed line (A) represents a theoretical maximum threshold of intake above which animals experience negative effects due to a surplus of PSMs or nutrients. The lower dashed line (B) represents a minimum threshold of intake below which animals are in a nutritional deficit or do not derive the potential positive benefit of PSMs. If meal sizes are too large (C), blood concentrations of PSMs or nutrients are in surplus, whereas if meal size is too small (D), there is a nutritional deficit or lack of potential therapeutic benefit from PSMs. Small meals consumed more frequently will allow animals to reach a "steady state", or balance, between deficiencies or surplus of PSMs or nutrients and this can then be maintained with a constant meal size and frequency interval $(\mathbf{E})$. However, even small meals consumed too frequently will result in concentrations of PSMs or nutrients above maximum thresholds $(\mathbf{F})$. The terminal slope of the concentration curves for each meal is constant to indicate a non-saturable elimination of the PSM or nutrient from the blood herbivores (Torregrossa et al., 2012). Specialist herbivores may not need to regulate intake of PSMs since their biotransformation system has evolved to process high doses of PSMs in a limited diet or because they absorb a lower proportion of PSMs consumed (Sorensen et al., 2004; Marsh et al., 2006b; Shipley et al., 2009). The mechanisms through which regulation of meal size and frequency occurs and why they differ among species are currently unknown. The leading proposed mechanisms are detection of PSMs in food and in blood plasma, conditioned learning, and intestinal or gustatory receptors (Foley et al., 1999; Torregrossa et al., 2011, 2012). To date, regulation of PSMs through meal size and intermeal interval has not been studied in aquatic herbivores. However, observations of feeding by free-ranging aquatic herbivores or documentation of intake of PSMs in captive aquatic animals readily lend themselves to investigation of PSM regulation via meal size and meal frequency. There is need to link dose of PSMs with mechanisms of detection to understand how PSMs alter foraging behavior in a variety of systems.

Regardless of mechanism or system, the concentration of PSM is likely to dictate feeding responses of herbivores across systems. As such, observations of temporal and spatial variation in feeding could be a result of temporal and spatial variation in PSM concentrations. For example, mammalian herbivores select specific trees (Moore and Foley, 2005; Degabriel et al., 2009; Moore et al., 2010) and aquatic herbivorous invertebrates select specific tissue types (Newman et al., 1996) thus avoiding consequences of toxic PSMs. To add to dietary complexity, feeding by herbivores can influence the concentration and distribution of both chemicals and nutrients. Environmental conditions that change over short (e.g., seasons) and long-time periods (e.g., global climate change) can also influence concentrations of PSMs (Bidart-Bouzat and Imeh-Nathaniel, 2008; Lindroth, 2010) as well as toxicity (Dearing et al., 2008; Dearing, 2012). In some cases, changes in PSM concentration may differ between terrestrial and aquatic systems. For example, concentrations may vary with fluctuations in hydration and ultraviolet light exposure in water-limited systems (Turtola et al., 2005; Chen et al., 2011), whereas these factors may be less variable in aquatic systems. There is a need for cross-system comparisons of how both qualitative and quantitative variation in chemicals and nutrients influence how herbivores regulate the dose of plants consumed over time.

Pharmacokinetic Mechanisms: Absorption, Distribution, Metabolism, and Excretion (ADME) The dose consumed does not always translate into a concentration that elicits a response. The concentration-time profile of a substrate in compartments can be modified by herbivores through mechanical and biochemical mechanisms that influence the absorption, distribution, metabolism, and excretion of substrates. 
These factors are collectively referred to in pharmacological literature as "ADME" and apply to both terrestrial and aquatic systems (Sotka et al., 2009). Pharmacokinetic studies that determine the concentration-time course may be more informative with respect to predictions of food intake than in vitro kinetic approaches that quantify enzyme activities. For example, different individuals consuming the same amount of PSM may not be exposed to the same concentration due to differences in the amount absorbed (Sorensen et al., 2004). Similarly, animals consuming different amounts of PSMs may have similar levels of exposure to PSMs. These subtle differences could have major implications for proper interpretation of in vitro studies. Both in vivo and in vitro studies investigating ADME of both PSMs and nutrients will offer insight into understanding the foraging phenotype of herbivores.

Absorption requires that the ingested substrate first be liberated, or released, from the plant biomass. For example, tannin-binding salivary proteins can bind to tannins and increase the availability of protein (Shimada, 2006). In addition, the physio-chemical characteristics of the stomach or the presence of microbes in the gut can influence the release of a PSM or nutrient from the food matrix (Foley et al., 1999; Gross et al., 2008). Once liberated, the substrate must then be absorbed where it can be distributed to the sites of action. The small intestine is the major site of absorption for terrestrial vertebrates, but other tissues also can be important and should be considered (e.g., gills and skin for aquatic species). Regardless of the site of the barrier, absorption can be passive or active depending on the electrochemical properties of the compound. There are ample reviews on factors such as the length and surface area of the intestine and the concentration and binding affinity of transporters that influence absorption of nutrients (Karasov and Martínez del Rio, 2007). In contrast, few studies have investigated how these factors influence the absorption of PSMs by herbivores (Sorensen et al., 2006). In addition, only a few studies have investigated how nutrient-PSM interactions influence absorption. For example, some tannins bind to dietary and endogenous proteins but disrupting these complexes in the gut significantly improves the protein economy of the animal and can improve the reproductive success (Degabriel et al., 2009).

One mechanism to minimize the response to PSMs is to actively transport them out of cells, back into the intestine against a concentration gradient (Sorensen and Dearing, 2006). PSMs that are removed from cells are then excreted in feces. Whereas some PSMs are substrates for these efflux transporters, others can inhibit or enhance their action (Wen et al., 2006; Zhou et al., 2008) and so influence the body concentrations of other PSMs ingested concurrently. This phenomenon, known as drug-drug-interactions, is well known in human pharmacology when drugs are ingested with other foods or drugs. Identification of the transporters that regulate absorption may shed light on herbivore tolerance to PSMs, reveal that herbivores avoid inhibitors or select inducers of these transporters, and explain how animals sequester chemicals in tissues.

Studies have highlighted the importance of paracellular absorption of many different compounds and the significant differences among groups of vertebrates in the capacity of this route (McWhorter et al., 2009). For example, paracellular absorption wherein molecules are passively absorbed through the aqueous channel in the tight junctions of adjoining cells appears to be particularly important in birds (Lavin and Karasov, 2008). Although enhanced paracellular absorption in birds relative to most mammals may compensate for shorter intestines of birds (Caviedes-Vidal et al., 2007), it may also expose birds to significantly greater amounts of water soluble PSMs (McWhorter et al., 2009), which can interfere with digestion and exert potentially toxic effects. Differences in the importance of paracellular absorption can translate to significantly different effects of PSMs on nutrient absorption (Skopec et al., 2010) and this offers an opportunity for researchers to investigate mechanisms responsible for nutrientPSM interactions. Paracellular absorption has not been investigated in fish but given their relatively short intestines, they too may rely on this route of absorption and thus be subjected to trade-offs similar to that observed in birds.

Once absorbed, the substrate is distributed throughout the body where it can be metabolized or react with tissues. The liver is the primary site of biotransformation of PSMs for vertebrates. In invertebrates, fat bodies and the digestive system, including the different gut compartments and the digestive gland, are responsible for the biotransformation of toxins (Keeley, 1985; Appel, 1993; Hyne and Maher, 2003; Rewitz et al., 2006; Gross et al., 2008). The enzymes responsible for the metabolism of drugs have been investigated extensively in laboratory and domestic mammals but far less so with respect to PSMs in wild herbivores, particularly aquatic ones (Dearing et al., 2005; Sorensen et al., 2006; Sotka et al., 2009). Drug metabolizing enzymes are extremely diverse and categorized broadly by function into Phase 1 enzymes such as the cytochrome P450s (CYPs) or Phase 2 enzymes such as glutathione S-transferases and glucuronyltransferases (Casarett et al., 2008). In general, metabolizing enzymes act to convert lipid soluble PSMs (and other ingested chemicals) into more watersoluble metabolites that can then be excreted (McLean and Duncan, 2006; Casarett et al., 2008). Individual mammals have scores of different drug metabolizing enzymes that are described elsewhere (for reviews see Dearing et al., 2005; McLean and Duncan, 2006; Casarett et al., 2008). The CYP enzymes of aquatic crustaceans responsible for detoxification differ from those of fish (Koenig et al., 2012), indicating differences between invertebrates and vertebrates. The recent genome sequencing of vertebrates (Margulies and Birney, 
2008) and invertebrates, including freshwater (Colbourne et al., 2011) and terrestrial (Adams et al., 2000; Whiteman et al., 2011) species has yielded new insight about the evolution of drug metabolizing enzymes (Asselman et al., 2012). For example, the CYP enzymes appear to have undergone repeated duplications, resulting in multiple gene copies for similar enzymes (Hu et al., 2008). Such genetic diversity may be critical for herbivores in the process of adapting to toxic or novel diets. Indeed Malenke et al. (2011) recently reported putative functional differences related to PSM intake within the subfamily of CYP2B in herbivorous woodrats. Future comparative genomic studies combined with functional analyses will be fruitful in understanding the evolution and diversity of drugmetabolizing enzymes and their influence on foraging phenotypes across taxa.

Herbivores, however, cannot be treated in isolation of their microbial symbionts. There is increasing evidence that most mammalian herbivores, and many invertebrate herbivores harbor large populations of microbes (bacteria, protozoa, and fungi) in their gut that play a variety of roles including making nutrients more available to the host animal (Stevens and Hume, 1998; Mountfort et al., 2002; Broderick et al., 2004; Chandler et al., 2008; Janson et al., 2008; Clements et al., 2009; Clark et al., 2010). Given the frequency of microbe-herbivore association, microbial communities may influence pharmacokinetics of nutrients and PSMs. From a nutritional perspective, gut microbes likely enhance the digestive and intestinal metabolic processing of nutrients in most herbivores. For example, gut microbes provide enzymes such as cellulases that efficiently digest plant material (He et al., 2009). Aquatic and terrestrial herbivorous Lepidoptera larvae harbor distinct communities of bacteria in the gut despite their small body size and the rapid passage of food through their gut, and these microbial communities differ depending on the plants eaten (Walenciak et al., 2002; Broderick et al., 2004). Whether bacteria are involved in the detoxification of PSM remains to be seen. However, bacteria isolated from the gut of aquatic Lepidoptera larvae feeding on a tannin-rich aquatic plant were less susceptible to the antibacterial effects of tannins than bacteria isolated from the gut of larvae fed with a tannin-free plant (Walenciak et al., 2002). The importance of gut bacteria in the toxic effects of Bacillus thuringiensis kurstaki on Lepiodoptera larvae also has been demonstrated (Broderick et al. 2004). Attempts to identify the gut bacterial community in zooplankton have been successful (Peter and Sommaruga, 2008), and might aid in determining the role of microorganisms in dealing with toxic phytoplankton. Recent evidence suggests that microbial gut communities of herbivorous fishes are more similar to those of herbivorous mammals than to carnivorous fishes, raising the interesting suggestion that fishes were among the first animals to ferment plant material (Sullam et al., 2012).
Another function of gut microbes may be the detoxification of ingested PSMs (Foley et al., 1999; Dearing et al., 2005; Chandler et al., 2008; Kohl et al., 2011; Kohl and Dearing, 2012). There is at least one example of this phenomenon in domestic ruminants. Jones and Megarrity (1986) showed that transfer of rumen contents from Indonesian goats to Australian goats allowed the latter to feed on Leucaena leaves without negative consequences. Synergistes jonesii was isolated as the microbe responsible for detoxification of the toxic metabolite (goitrogen 3-hydroxy-4 $(1 \mathrm{H})$ pyridone) generated by the rumen metabolism of the PSM mimosine (Rincon et al., 1998). This bacterium has been readily transferred between individual animals with clear benefits to the host (Jones and Megarrity, 1986). Curiously, none of the players in this system (microbe, plant, herbivore) has a long evolutionary history with the others. In addition to this example, detoxification of PSMs by gut microbes has been suggested for the unique and diverse microbial community found in the gut of a herbivorous rodent, the woodrat (Kohl et al., 2011). Moreover, the diversity of the microbial community appears to be a function of the host's evolutionary experience with PSMs, such that more diverse communities are present in herbivores with previous experience to particular PSMs compared to novel ones (Kohl and Dearing, 2012). This microbial diversity may be key in reducing the concentrations of PSMs prior to absorption by the host. The first evidence that microbial detoxification of ingested PSMs occurs in fish has been reported (Guan et al., 2009). There are other examples in domestic ruminants (Majak, 1992) where an increase in toxicity occurs via microbial modification. Although hindgut fermenters are expected to benefit from microbial detoxification of PSMs less than foregut fermenters, microbes inhabit the mucosal lining of the intestine prior to the cecum in many terrestrial (Yamamoto et al., 2009; Frey et al., 2010) and aquatic animals (Mondal et al., 2008; Ganguly and Prasad, 2011). Additional studies are needed to identify the positive and negative influences that microbial communities have on herbivores with either complex or simplified digestive tracts, such as those found in marine and freshwater invertebrates (Brunet et al., 1994; Freese and Schink, 2011).

The recently developed technique of metagenomics is likely to reveal more about the function of gut microbes and perhaps result in some paradigm shifts (Ley et al., 2006, 2008). For example, the microbial floras of giant and red pandas are exceptional for herbivorous mammals in that they are more similar to that of their carnivorous relatives than to other herbivores (Ley et al., 2008). A recent metaanalysis suggests that not only do fish have specialized gut microflora, but that the bacterial communities in fish are closely related to those from terrestrial mammals (Sullam et al., 2012). A second frontier in both terrestrial and marine systems is in understanding the impact of nutrient and PSM concentrations on the interactions between gut microflora 
and the immune function of the host (Reynaud et al., 2008; Hooper and Macpherson, 2010; Perez et al., 2010).

In general, herbivores are predicted to invest in mechanisms that regulate the liberation, absorption, distribution, metabolism, and excretion of PSMs and nutrients thus minimizing inadequate or surplus concentrations of these dietary components. Investment in particular mechanisms may be influenced by the extent to which nutrients or PSMs are more important for a particular herbivore. It is likely that many mechanisms are yet to be discovered, particularly in non-model organisms.

Pharmacodynamic Mechanisms Compared to our understanding of pharmacokinetic mechanisms, we know even less about pharmacodynamic (PD) mechanisms. The concentration-response relationship, referred to as pharmacodynamics, describes how a known concentration of a substrate elicits a behavioral or physiological response in herbivores (Fig. 1). In general, it represents the extent to which a chemical reacts with the body to cause an observable response. Variation in food intake has been the response measured most commonly in herbivores (Ibelings and Havens, 2008; Behmer, 2009; Martins and Vasconcelos, 2009; Torregrossa and Dearing, 2009). Other responses such as locomotor activity (Sorensen et al., 2005c), metabolic rates (Bozinovic and Novoa, 1997; Sorensen et al., 2005c), thermoregulation (McLister et al., 2004), organ damage (Fu et al., 2004), water balance (Dearing et al., 2002; Mangione et al., 2004), and acid-base homeostasis (Foley et al., 1995) also have been investigated. Only a single study has examined the effect of blood concentration of PSMs on intake in a wild mammal (Mclean et al., 2007), which may be critical to predicting foraging phenotypes in nature. The link between intake, blood (or other body compartment) concentration, and more specifically, distribution to specific tissues deserves attention if we want to know the mechanism of action of PSMs. Given the difficulty in collecting repeated blood samples for PSM concentrations for most animals, an alternative and potentially more effective pharmacodynamic approach would be to measure efficacy (the maximum response for a given dose), potency (the dose needed to produce a response), slope (how much or how little the difference is between the dose that causes no effect and one that causes a maximum effect), and variation of the dose-response curve within and between species administered different doses of PSMs (Fig. 1).

Identifying a mode of action that elicits a response is more challenging than investigating enzyme metabolism. Some PSMs are known to have highly specific targets such as the inhibition of $\mathrm{Na}^{+} / \mathrm{K}^{+}$ATPase by cardenolides (Petschenka et al., 2012) and cardiac glycosides (Holzinger and Wink, 1996) and inhibition of succinate dehyrogenase by papyriferic acid from birch (McLean et al., 2009; Forbey et al., 2011). Other PSMs interact with nutrients to cause broad pharmacological responses such as oxidative stress (Aucoin et al., 1995), or work synergistically with other PSMs to elicit responses (Guillet et al., 2000; Wen et al., 2006). Others may exert their effects indirectly through multiple pathways. For example, jensenone, a formylated phloroglucinol compound in Eucalyptus, whose intake is closely regulated by folivorous marsupials, exerts its effects by binding to amine groups on critical molecules in the gastrointestinal tract, leading to a loss of metabolic function (McLean et al., 2004), followed by the release of 5hydroxytryptamine (5HT), which in turn may mediate an emetic response leading to a conditioned aversion (Lawler et al., 1998). Not surprisingly, species differ in their doseresponse curves (Majak, 1992; Forbey et al., 2011). Moreover, the molecular targets of most PSMs that elicit the behavioral or physiological consequences (e.g., basal metabolic rate, energy excretion, weight loss, increased body temperature) are not always apparent. Emerging advances in molecular modeling provide ecologists with in silico techniques that can reveal the most likely molecular targets of specific PSMs with known structures (Forbey et al., 2011). Coupling molecular modeling with in vitro and in vivo pharmacodynamic studies will facilitate understanding how differences in the interactions between nutrients, PSMs, and target receptors explain foraging patterns of herbivores.

\section{Predicting Foraging Patterns}

Chemistry-Herbivore Patterns Although pharm-ecological approaches have largely been applied in controlled laboratory settings, the ultimate aim is to use the insight from this framework to predict foraging of herbivores in the field. Free-ranging animals have many more choices, broader diets, and other competing costs, such as predation, than animals in captivity. For example, the ability of herbivores under laboratory conditions to regulate dose through frequent, smaller meals may be constrained in the field if animals cannot meet biomass needs from a single plant, or if they expend energy or have greater predation risk when moving between foraging patches (Wiggins et al., 2006b; Nersesian et al., 2011). Consequently, we should not necessarily expect simple correlations between the occurrence of one or several PSMs or nutrients and diet choice from field studies even when there are very strong relationships between particular PSMs, nutrients, and intake in captive studies.

Moreover, animals will rarely, if ever, encounter the full range of variation in intraspecific variation of PSMs in a species. Most PSMs are synthesized through the action of multiple genes, and this results in concentrations of PSMs being normally distributed among different plants (Andrew 
et al., 2007). Consequently, animals frequently encounter the median concentrations but rarely the high and low extremes. Thus, the power to detect relationships between feeding and PSM or nutrient concentrations will be low unless a large number of observations are made and a large number of plants are examined. Doing so requires highthroughput techniques such as near infrared reflectance spectroscopy (NIRS). This analytical technique relies on establishing relationships between traits of interest (e.g., nitrogen, specific PSM) and the NIR spectrum of the sample. Once this relationship is defined statistically, the traits can be predicted in a large number of additional samples by collecting the spectrum alone (Foley et al., 1998; Stolter et al., 2006). Although NIRS has mostly been applied to terrestrial plants, it also works well with aquatic plants such as seagrass (Lawler et al., 2006) and brown macroalgae (Sargassum, Hay et al., 2010). The biggest benefit is being able to predict complex multi-dimensional traits such as the overall palatability of a plant to herbivores. With this approach, Moore et al. (2010) used NIRS to map the palatability of multiple home ranges of koalas in an area of forest, and they found that the palatability measure predicted feeding better than measuring PSMs and nutrients separately. NIRS, thus, allows measurement of complex traits of many plants and over large areas and a more comprehensive evaluation of the nutritional and chemical landscape. These traits can then be linked to mechanisms employed by populations or species with exceptionally low or high tolerance to these traits.

In addition to high throughput approaches, genetic modification holds promise for predicting foraging phenotypes of free-ranging herbivores (Kessler et al., 2004, 2008; Wu and Baldwin, 2009). For example, silencing of the jasmonate cascade in Nicotiana attenuata improved the performance of specialist herbivores and allowed nonadapted generalist herbivores to attack (Kessler et al., 2004). Insect transgenesis has been used to manipulate agricultural and medical insect pests (Fraser, 2012), and it could also be used to observe how foraging phenotypes of herbivores are influenced by control of pharmacokinetic (e.g., detoxification enzymes) and pharmacodymanic (e.g., target receptors) mechanisms. Genetic manipulations of free-ranging species offer exciting opportunities for examining the underlying mechanism of herbivore responses to variable diet quality.

An understanding of which components of the diet an animal is regulating is important in applying pharmecological frameworks in the field. One particularly useful approach is the geometric modeling framework of Simpson and Raubenheimer (Raubenheimer and Simpson, 1997; Simpson and Raubenheimer, 2001; Simpson et al., 2010). This graphical approach allows preferences for one nutrient or PSM to be evaluated against multiple others while taking into account the animal's current nutritional state. An animal feeding on a nutritionally balanced food that contains a manageable concentration of PSMs could eat sufficient amounts of that food to meet requirements for multiple nutrients (e.g., protein and energy), whereas an imbalanced food might require ingesting too much of one nutrient or PSM to obtain sufficient quantities of another. The geometric framework then becomes a powerful tool for observing tradeoffs and compromises, and is equally applicable to examine tradeoffs among multiple nutrients, nutrients and PSMs, or even nutrients and medicines (Raubenheimer and Simpson, 2009). Moreover, it can used to identify how genetic modification or chemical inhibition or induction of pharmacokinetic or pharmacodynamic mechanisms influence tradeoffs.

The geometric framework has been most widely applied to captive species (Fanson et al., 2009; Mayntz et al., 2009; Miller et al., 2009; Jensen et al., 2011). However, it has been successfully used in free ranging herbivores as well (Wright et al., 2003). A study in wild primates showed that, contrary to prevailing views, spider monkeys prioritized acquisition of protein not bound by tannins over energy across many days of individual foraging (Felton et al., 2009). In contrast, similar studies of wild gorillas found no prioritization of protein (Rothman et al., 2011). This framework should be applied more broadly in multiple taxa to continue bridging the gap between a functional understanding of foraging in individual animals to that of whole communities (Simpson et al., 2010).

\section{Conclusions and Pharm-Ecological Questions}

The majority of studies in plant-herbivore interactions have focused solely on the effects of PSMs or nutrients on intake, such that nutritional demands result in an increase in total intake of the required nutrient, whereas toxicity of PSMs results in a decrease in total intake. We hypothesize that the variable patterns of intake observed in herbivores cannot be fully explained unless we understand the mechanisms by which dose, concentration, and response are related, and how they can be modified by herbivores. We also hypothesize that a pharm-ecological approach can overcome and actually capitalize on differences between aquatic and terrestrial systems to answer how chemistry, ecology, and taxonomy explain foraging phenotypes. Although all animals use highly conserved mechanisms to regulate the doseconcentration-response relationship, each animal will likely have an unique pharmacokinetic and pharmacodynamic phenotype that is dependent on various combinations of genetic, behavioral, and biochemical mechanisms. An understanding of the mechanisms driving similarities and differences among taxonomic groups of plants and herbivores 
will advance our understanding of the evolution of plantherbivore interactions. We offer some questions that could be addressed through collaborations between ecologists studying aquatic and terrestrial systems:

\section{Does the Physio-chemical Environment Influence} Foraging Phenotypes? Although terrestrial and aquatic plants provide similar resources (e.g., protein, fats, and carbohydrates) to herbivores and share many of the same broad classes of secondary metabolites (see Sotka et al., 2009), there are notable differences. For example, cyanogenic glycosides, glucosinolates, or tetraterpenoids have either not been reported or are not produced by marine algae. How might terrestrial and aquatic herbivores respond to novel classes of PSMs only found in the other system? Do aquatic herbivores have specialized mechanisms to deal with more water soluble PSMs generated in the lower oxygen availability in marine environments (Kong et al., 2010) than terrestrial herbivores? Are there differences in receptors for PSMs between aquatic and terrestrial herbivores that depend on the sensitivity to detect water or lipid-soluble PSMs? Because herbivores in freshwater systems experience a gradient from dry to wet, do they possess PK-PD mechanisms that are functional in both marine and terrestrial systems? Are aquatic herbivores more likely to experience synergistic chemical consequences than terrestrial herbivores? Have ecologists overlooked the consequences of inadvertently consuming cryptic toxins from small epiphytes living on larger plants (Cruz-Rivera and Hay, 2003; Sotka et al., 2009) by focusing only on host plant traits (Porras-Alfaro and Bayman, 2011)?

2. Does the Ecological Extent of Herbivory Influence PKPD Mechanisms and Foraging Phenotypes? Do species that transition between carnivory, omnivory, and degree of specialized herbivory during their life span have more generalized or plastic PK-PD mechanisms than species without these transitions? For example, terrestrial vertebrates, aquatic, and particularly marine herbivores, are largely generalists and rarely specialize on particular foods (Poore et al., 2008; Shipley et al., 2009). Moreover, herbivorous fishes often are carnivores as juveniles and transition to herbivory with age (Horn, 1989). Is there a relationship between the expression and diversity of PK mechanism and dietary transition points that is consistent among taxa? Certainly, shifts in generalism and omnivory will make linking laboratory pharm-ecological studies to field foraging patterns difficult, as the link between diet and response is clearer in specialist herbivores. However, broadscale approaches such as state-of-the-art genomic and proteomic techniques can compare the diversity of detoxification mechanisms (Thiyagarajan and Qian, 2008; Whalen et al.,
2008; Browning et al., 2010; Glenn et al., 2010; Itokawa et al., 2010; Shawahna et al., 2011; Eyckmans et al., 2012) and microbial communities (Masahira et al., 2009; Matteotti et al., 2011; Langille et al., 2012; Weinstock, 2012) relative to dietary diversity. These emerging approaches offer potential to compare and contrast pharm-ecological mechanisms and foraging phenotypes across wide taxonomic groups

3. Does Phylogenetic Diversity Influence PK-PD? Relative to terrestrial herbivores, there is a broader phyletic diversity of herbivores in the ocean than on land. While herbivory is largely the domain of two terrestrial groups (insects and mammals), there are at least six phyla that consume benthic seaweeds: vertebrates (fish, reptiles, and manatees), arthropods (insects, amphipods, isopods, crabs), echinoderms, annelids, pycnogonids, and mollusks (chitons, snails, sea slugs, abalone). Moreover, herbivory arose independently within dozens of clades of more recent origin (Vermeij and Lindberg, 2000). Given the phylogenetic diversity within marine systems, do marine herbivores as a group, use a broader suite of mechanisms to 'deal' with the challenges of consuming chemically-defended and nutritionally-poor foods relative to terrestrial consumers?

The pharm-ecological questions and approaches provided here may allow researchers to explain and predict how intake, dose, and herbivore morphology, physiology, and taxonomy interact to influence kinetic and dynamic interactions between plants and herbivores. The true value of the pharm-ecological approach requires interdisciplinary collaboration among aquatic and terrestrial ecotoxicologists or physiologists who focus solely on mechanisms, and ecologists who look primarily at ecological patterns and processes. Pharm-ecology provides a common language and approach to meet a future objective: scaling a functional understanding of phytochemical acquisition and avoidance in individual organisms to the more complex interactions at higher levels of biological organization and comparing these scales across diverse systems.

Acknowledgments We thank Randi Rotjan and Joshua Idjadi and four anonymous reviewers for comments that improved the manuscript and Kathy Smith for assistance with formatting the manuscript. We thank the National Science Foundation (0827239 to JSF) for funding the Pharm-Ecology Symposium at the Society for Integrative and Comparative Biology 2010 that stimulated many of the ideas in this manuscript. We also thank National Science Foundation Grant IOS-0817527 and DEB-1146194 to MDD and JSF, respectively, the Australian Research Council Discovery Grant DP0986142 to WJF, the German Science Foundation DFG, CRC454 project A2 to EMG, and the National Research Initiative of the USDA National Institute of Food and Agriculture 2007-35302-18351 to CMO. 


\section{References}

Adams, M. D., Celniker, S. E., Holt, R. A., Evans, C. A., Gocayne, J. D., Amanatides, P. G., et al. 2000. The genome sequence of Drosophila melanogaster. Science 287:2185-2195.

AMSLER, C. D. 2008. Algal Chemical Ecology. Springer, Berlin.

Andrew, R. L., Peakall, R., Wallis, I. R., and Foley, W. J. 2007. Spatial distribution of defense chemicals and markers and the maintenance of chemical variation. Ecology 88:716-728.

APPEL, H. M. 1993. The insect gut lumen: Physiochemistry and impact on plant allelochemicals and nutrients, pp 209-223, in E. A. Bernays (ed.), Insect-Plant Interactions. CRC Press, Inc.

APPEL, H. M. and SCHUlTZ, J. C. 1994. Oak tannins reduce effectiveness of thuricide (Bacillus thuringiensis) in the gypsy-moth (Lepidoptera, Lymantriidae). J. Econ. Entomol. 87:1736-1742.

Asselman, J., Glaholt, S. P., Smith, Z., Smagghe, G., Janssen, C. R., Colbourne, J. K., et al. 2012. Functional characterization of four metallothionein genes in Daphnia pulex exposed to environmental stressors. Aquat. Toxicol. 110:54-65.

Aucoin, R., Guillet, G., Murray, C., Philogene, B. J. R., and ARNASON, J. T. 1995. How do insect herbivores cope with the extreme oxidative stress of phototoxic host plants. Arch. Insect Biochem. Physiol. 29:211-226.

Barbehenn, R. V. and Constabel, C. P. 2011. Tannins in plantherbivore interactions. Phytochemistry 72:1551-1565.

Barboza, P., PArker, K., and Hume, I. 2009. Integrative Wildlife Nutrition. Springer, Berlin.

BeHMER, S. T. 2009. Insect herbivore nutrient regulation. Annu. Rev. Entomol. 54:165-187.

Behmer, S. T., Simpson, S. J., and Raubenheimer, D. 2002. Herbivore foraging in chemically heterogeneous environments: Nutrients and secondary metabolites. Ecology 83:2489-2501.

Bernays, E. A., Bright, K. L., GonZalez, N., and ANGel, J. 1994. Dietary mixing in a generalist herbivore - tests of 2 hypotheses. Ecology 75:1997-2006.

BidART-BouZAT, M. G. and IMEH-NAthaniel, A. 2008. Global change effects on plant chemical defenses against insect herbivores. $J$. Integr. Plant Biol. 50:1339-1354.

Boyle, R. R., Mclean, S., Brandon, S., and Wiggins, N. 2005. Rapid absorption of dietary 1,8-cineole results in critical blood concentration of cineole and immediate cessation of eating in the common brushtail possum (Trichosurus vulpecula). J. Chem. Ecol. 31:2775-2790.

BozinOvic, F. and NovoA, F. F. 1997. Metabolic costs of rodents feeding on plant chemical defenses: A comparison between an herbivore and an omnivore. Comp. Biochem. Physiol. A Mol. Integr. Physiol. 117:511-514.

Broderick, N., RAFFa, K., GoOdman, R., and HANDElsman, J. 2004. Census of the bacterial community of the gypsy moth larval midgut by using culturing and culture-independent methods. Appl. Environ. Microbiol. 70:293-300.

Browning, S. L., Tarekegn, A., Bekele, E., Bradman, N., and THOMAS, M. G. 2010. CYP1A2 is more variable than previously thought: A genomic biography of the gene behind the human drug-metabolizing enzyme. Pharmacogenet. Genomics 20:647664.

Brunet, M., ARnAud, J., and MAZZA, J. 1994. Gut structure and digestive cellular processes in marine Crustacea. Oceanogr. Mar. Biol. 32:335-367.

Casarett, L. J., Doull, J., and Klaassen, C. D. 2008. Casarett and Doull's Toxicology: The Basic Science of Poisons. McGraw-Hill, New York, NY.

Caviedes-Vidal, E., McWhorter, T. J., Lavin, S. R., Chediack, J. G., Tracy, C. R., and Karasov, W. H. 2007. The digestive adaptation of flying vertebrates: High intestinal paracellular absorption compensates for smaller guts. Proc. Natl. Acad. Sci. U. S. A. 104:19132-19137.

Chambers, J. E. and Yarbrough, J. D. 1976. Xenobiotic biotransformation systems in fishes. Comp. Biochem. Physiol. C Pharmacol. Toxicol. Endocrinol. 55:77-84.

Chandler, S. M., Wilkinson, T. L., and Douglas, A. E. 2008. Impact of plant nutrients on the relationship between a herbivorous insect and its symbiotic bacteria. Proc. R. Soc. Lond. B Biol. Sci. 275:565-570.

Chen, Y. H., Guo, Q. S., LiU, L., LiaO, L., and ZhU, Z. B. 2011. Influence of fertilization and drought stress on the growth and production of secondary metabolites in Prunella vulgaris L. J. Med. Plant Res. 5:1749-1755.

Chote, J. H. and Clements, K. D. 1998. Vertebrate herbivores in marine and terrestrial environments: A nutritional ecology perspective. Annu. Rev. Ecol. Syst. 29:375-403.

Clark, E. L., Karley, A. J., and Hubbard, S. F. 2010. Insect endosymbionts: Manipulators of insect herbivore trophic interactions? Protoplasma 244:25-51.

Clements, K. D., Raubenheimer, D., and Choat, J. H. 2009. Nutritional ecology of marine herbivorous fishes: Ten years on. Funct. Ecol. 23:79-92.

Colbourne, J. K., Pfrender, M. E., Gilbert, D., Thomas, W. K., TUCKER, A., OAKLEY, T. H., et al. 2011. The ecoresponsive genome of Daphnia pulex. Science 331:555-561.

Cruz-Rivera, E. and HAY, M. E. 2003. Prey nutritional quality interacts with chemical defenses to affect consumer feeding and fitness. Ecol. Monogr. 73:483-506.

DEARING, M. D. 2012. Temperature-dependent toxicity in mammals with implications for herbivores: A review. J. Comp. Physiol. B, Biochem. Syst. Environ. Physiol. 183:43-50.

Dearing, M. D., Mangione, A. M., and Karasov, W. H. 2000. Diet breadth of mammalian herbivores: Nutrient versus detoxification constraints. Oecologia 123:397-405.

Dearing, M. D., Mangione, A. M., and Karasov, W. H. 2002. Ingestion of plant secondary compounds causes diuresis in desert herbivores. Oecologia 130:576-584.

Dearing, M. D., Foley, W. J., and McLean, S. 2005. The influence of plant secondary metabolites on the nutritional ecology of herbivorous terrestrial vertebrates. Annu. Rev. Ecol. Evol. Syst. 36:169-189.

Dearing, M. D., Forbey, J. S., McLister, J. D., and SAntos, L. 2008. Ambient temperature influences diet selection and physiology of an herbivorous mammal, Neotoma albigula. Physiol. Biochem. Zool. 81:891-897.

Degabriel, J., Foley, W. J., and Wallis, I. R. 2002. The effect of excesses and deficiencies in amino acids on the feeding behaviour of the common brushtail possum (Trichosurus vulpecula). J. Comp. Physiol. B, Biochem. Syst. Environ. Physiol. 172:607-617.

Degabriel, J. L., Moore, B. D., Foley, W. J., and Johnson, C. N. 2009. The effects of plant defensive chemistry on nutrient availability predict reproductive success in a mammal. Ecology 90:711-719.

DEMOTT, W. R. 1999. Foraging strategies and growth inhibition in five daphnids feeding on mixtures of a toxic cyanobacterium and a green alga. Freshw. Biol. 42:263-274.

Derby, C. D. and Sorensen, P. W. 2008. Neural processing, perception, and behavioral responses to natural chemical stimuli by fish and crustaceans. J. Chem. Ecol. 34:898-914.

Dobler, S., Petschenka, G., and Pankoke, H. 2011. Coping with toxic plant compounds - the insect's perspective on iridoid glycosides and cardenolides. Phytochemistry 72:1593-1604.

Duffy, J. E. and PAUL, V. J. 1992. Prey nutritional quality and the effectiveness of chemical defenses against tropical reef fishes. Oecologia 90:333-339. 
Duncan, A. J., Elwert, C., Villalba, J. J., Yearsley, J., Pouloupoulou, I., and Gordon, I. J. 2007. How does pattern of feeding and rate of nutrient delivery influence conditioned food preferences? Oecologia 153:617-624.

Dziba, L. E., Hall, J. O., and Provenza, F. D. 2006. Feeding behavior of lambs in relation to kinetics of 1,8-cineole dosed intravenously or into the rumen. J. Chem. Ecol. 32:391-408.

Erhard, D., Pohnert, G., and Gross, E. M. 2007. Chemical defense in Elodea nuttallii reduces feeding and growth of aquatic herbivorous Lepidoptera. J. Chem. Ecol. 33:1646-1661.

EycKMANS, M., BENOOT, D., VAN RAEMDONCK, G. A. A., ZEgEls, G., VAn Ostade, X. W. M., WitTers, E., et al. 2012. Comparative proteomics of copper exposure and toxicity in rainbow trout, common carp and gibel carp. Comp. Biochem. Physiol. D Genomics Proteomics 7:220-232.

Fanson, B. G., Weldon, C. W., Perez-Staples, D., Simpson, S. J., and TAYLOR, P. W. 2009. Nutrients, not caloric restriction, extend lifespan in queensland fruit flies (Bactrocera tryoni). Aging Cell 8:514-523.

Favreau, A., Baumont, R., Duncan, A. J., and Ginane, C. 2010. Sheep use preingestive cues as indicators of postingestive consequences to improve food learning. J. Anim. Sci. 88:1535-1544.

Felton, A. M., Felton, A., Raubenheimer, D., Simpson, S. J., Foley, W. J., WooD, J. T., et al. 2009. Protein content of diets dictates the daily energy intake of a free-ranging primate. Behav. Ecol. 20:685-690.

Field, K., Bachmanov, A., Mennella, J., Beauchamp, G., and KIMBALL, B. 2009. Protein hydrolysates are avoided by herbivores but not by omnivores in two-choice preference tests. PLoS One 4:E4126.

FolEY, W. and MCARTHUR, C. 1994. The effects and costs of ingested allelochemicals in mammals: An ecological perspective, pp. 370 391, in D. Chivers and P. Langer (eds.), The Digestive System in Mammals: Food, Form and Function. Cambridge University Press, Cambridge.

Foley, W. J., MCLEAN, S., and CoRK, S. J. 1995. The effects of plant allelochemicals on acid-base metabolism; the final common pathway. J. Chem. Ecol. 21:721-743.

Foley, W. J., McIlwee, A., LaWler, I., Aragones, L., WoOlnough, A. P., and BERDING, N. 1998. Ecological applications of near infrared reflectance spectroscopy a tool for rapid, cost-effective prediction of the composition of plant and animal tissues and aspects of animal performance. Oecologia 116:293-305.

Foley, W., IASON, G., and MCARTHUR, C. 1999. Role of plant secondary metabolites in the nutritional ecology of mammalian herbivores - how far have we come in 25 years? pp. 203-274, in H. J. Jung and G. Fahey (eds.), International Symposium on the Nutrition of Herbivores. American Society of Animal Science, Savoy IL.

Forbey, J. S., Harvey, A. L., Huffman, M. A., Provenza, F. D., SulLIVAN, R., and TASDEMIR, D. 2009. Exploitation of secondary metabolites by animals: A response to homeostatic challenges. Integr. Comp. Biol. 49:314-328.

Forbey, J. S., Pu, X. Z., XU, D., Kielland, K., and Bryant, J. 2011. Inhibition of snowshoe hare succinate dehydrogenase activity as a mechanism of deterrence for papyriferic acid in birch. J. Chem. Ecol. 37:1285-1293.

FRASER, M. J. 2012. Insect transgenesis: Current applications and future prospects, pp. 267-289, in M. R. Berenbaum (ed.), Annu. Rev. of Entomol. Annual Reviews, Palo Alto.

FreELAND, W. J. and JANZEN, D. H. 1974. Strategies in herbivory by mammals: The role of plant secondary compounds. Am. Nat. 108:269-289.

FreEse, H. M. and SchinK, B. 2011. Composition and stability of the microbial community inside the digestive tract of the aquatic crustacean Daphnia magna. Microb. Ecol. 62:882-894.
Frey, J., Pell, A., Berthiaume, R., Lapierre, H., Lee, S., Ha, J., et al. 2010. Comparative studies of microbial populations in the rumen, duodenum, ileum and faeces of lactating dairy cows. $J$. Appl. Microbiol. 108:1982-1993.

Frye, G. G., Connelly, J. W., Musil, D. D., and Forbey, J. F. 2013. Phytochemistry predicts habitat selection by an avaian herbivore at multiple spatial scales. Ecology 92:308-314.

FU, P. P., XIA, Q. S., LIN, G., and ChOU, M. W. 2004. Pyrrolizidine alkaloids - genotoxicity, metabolism enzymes, metabolic activation, and mechanisms. Drug Metab. Rev. 36:1-55.

Ganguly, S. and PRASAD, A. 2011. Microflora in fish digestive tract plays significant role in digestion and metabolism. Rev. Fish Biol. Fish. 22:11-16.

Ginane, C., Duncan, A. J., Young, S. A., Elston, D. A., and Gordon, I. J. 2005. Herbivore diet selection in response to simulated variation in nutrient rewards and plant secondary compounds. Anim. Behav. 69:541-550.

Glenn, A. E., Karagianni, E. P., Ulndreaj, F., and Boukouvala, S. 2010. Comparative genomic and phylogenetic investigation of the xenobiotic metabolizing arylamine n-acetyltransferase enzyme family. FEBS Lett. 584:3158-3164.

GovenoR, H. L., Schultz, J. C., and ApPel, H. M. 1997. Impact of dietary allelochemicals on gypsy moth (Lymantria dispar) caterpillars: Importance of midgut alkalinity. J. Insect Physiol. 43:1169-1175.

Gross, E. and BAKKER, E. 2012. The role of plant secondary metabolites in freshwater macrophyte-herbivore interactions: Limited or unexplored chemical defences? pp. 154-169, in G. Iason, M. Dicke, and S. Hartley (eds.), The Integrative Role of Plant Secondary Metabolites in Ecological Systems. British Ecological Society/Cambridge University Press, Sussex, UK.

Gross, E. M., BRUNE, A., and WALENCIAK, O. 2008. Gut pH, redox conditions and oxygen levels in an aquatic caterpillar: Potential effects on the fate of ingested tannins. J. Insect Physiol. 54:462471.

Guan, S., He, J. W., Young, J. C., Zhu, H. H., Li, X. Z., Ji, C., et al. 2009. Transformation of trichothecene mycotoxins by microorganisms from fish digesta. Aquaculture 290:290-295.

Guillet, G., Harmatha, J., Waddell, T. G., Philogene, B. J. R., and ARNASON, J. T. 2000. Synergistic insecticidal mode of action between sesquiterpene lactones and a phototoxin, alphaterthienyl. Photochem. Photobiol. 71:111-115.

Gustafsson, S. and HANSSON, L. A. 2004. Development of tolerance against toxic cyanobacteria in Daphnia. Aquat. Ecol. 38:37-44.

Haley, S. L., Lamb, J. G., Franklin, M. R., Constance, J. E., and DEARING, M. D. 2008. "Pharm-ecology" of diet shifting: Biotransformation of plant secondary compounds in creosote (Larrea tridentata) by a woodrat herbivore, Neotoma lepida. Physiol. Biochem. Zool. 81:584-593.

HAY, M. E. and FENICAL, W. 1988. Marine plant-herbivore interactions - the ecology of chemical defense. Annu. Rev. Ecol. Syst. 19:111145.

Hay, M. E., Duffy, J. E., Pfister, C. A., and Fenichl, W. 1987. Chemical defense against different marine herbivores: Are amphipods insect equivalents? Ecology 68:1567-1580.

Hay, K. B., Millers, K. A., Poore, A. G. B., and Lovelock, C. E. 2010. The use of near infrared reflectance spectrometry for characterization of brown algal tissue1. J. Phycol. 46:937-946.

He, L., Zhang, Z., Xie, C., HaO, B., Wang, C., and He, G. 2009. Isolation of cellulose-producing microbes from the intestine of grass carp (Ctenopharyngodon idellus). Environ. Biol. Fish $86: 131-135$.

HolzINGER, F. and WINK, M. 1996. Mediation of cardiac glycoside insensitivity in the monarch butterfly (Danaus plexippus): Role of an amino acid substitution in the ouabain binding site of $\mathrm{Na}+$, K+-ATPase. J. Chem. Ecol. 22:1921-1937. 
Hooper, L. V. and MACPHERSON, A. J. 2010. Immune adaptations that maintain homeostasis with the intestinal microbiota. Nat. Rev. Immunol. 10:159-169.

HoRN, M. H. 1989. Biology of marine herbivorous fishes. Oceanogr. Mar. Biol. Annu. Rev. 27:641-664.

Hu, S. Y., Wang, H. Y., Knisely, A. A., Reddy, S., Kovacevic, D., LIU, Z., et al. 2008. Evolution of the CYP2ABFGST gene cluster in rat, and a fine-scale comparison among rodent and primate species. Genetica 133:215-226.

HuANG, T. F., JANDER, G., and DE VOS, M. 2011. Non-protein amino acids in plant defense against insect herbivores: Representative cases and opportunities for further functional analysis. Phytochemistry 72:1531-1537.

HunTER, M. D. and SChultz, J. C. 1993. Induced plant defenses breached - phytochemical induction protects an herbivore from disease. Oecologia 94:195-203.

HYNE, R. V. and MAHER, W. A. 2003. Invertebrate biomarkers: Links to toxicosis that predict population decline. Ecotoxicol. Environ. Saf. 54:366-374.

IBELINGS, B. W. and HaVEns, K. E. 2008. Cyanobacterial toxins: A qualitative meta-analysis of concentrations, dosage and effects in freshwater, estuarine and marine biota, pp. 675-732, in Cyanobacterial Harmful Algal Blooms: State of the Science and Research Needs, Springer, New York.

Itokawa, K., Komagata, O., Kasai, S., OKamura, Y., Masada, M., and TOMITA, T. 2010. Genomic structures of CYP9M10 in pyrethroid resistant and susceptible strains of Culex quinquefasciatus. Insect Biochem. Mol. Biol. 40:631-640.

Janson, E. M., StiReman, J. O., Singer, M. S., and ABbot, P. 2008. Phytophagous insect-microbe mutualisms and adaptive evolutionary diversification. Evolution 62:997-1012.

Jensen, K., Mayntz, D., Toft, S., Raubenheimer, D., and Simpson, S. J. 2011. Nutrient regulation in a predator, the wolf spider Pardosa prativaga. Anim. Behav. 81:993-999.

JONES, R. J. and MEGARRITY, R. G. 1986. Successful transfer of DHPdegrading bacteria from hawaiian goats to australian ruminants to overcome the toxicity of Leucaena. Aust. Vet. J. 63:259-262.

KARASOV, W. and HuME, I. 1997. Vertebrate gastrointestinal system, pp. 407-480, in W. Dantzler (ed.), Handbook of Comparative Physiology. American Physiological Society, Bethesda.

Karasov, W. and Martínez Del Rio, C. 2007. Physiological Ecology: How Animals Process Energy, Nutrients, and Toxins. Princeton University Press, Princeton.

KATAGI, T. 2010. Bioconcentration, bioaccumulation, and metabolism of pesticides in aquatic organisms. Rev. Environ. Contam. Toxicol. 204:1-132.

KeELEY, L. L. 1985. Biochemistry and physiology of the insect fat body, pp. 211-228, in G. A. Kerkut and L. I. Gilbert (eds.), Comprehensive Insect Physiology, Biochemistry and Pharmacology. Pergamon, New York

Kessler, A., HalitschKe, R., and BALDWIN, I. T. 2004. Silencing the jasmonate cascade: Induced plant defenses and insect populations. Science 305:665-668.

Kessler, D., GASE, K., and BALDWIN, I. T. 2008. Field experiments with transformed plants reveal the sense of floral scents. Science 321:1200-1202.

Koenig, S., Fernandez, P., and Sole, M. 2012. Differences in cytochrome P450 enzyme activities between fish and crustacea: Relationship with the bioaccumulation patterns of polychlorobiphenyls (PCBS). Aquat. Toxicol. 108:11-17.

Kohl, K. D. and Dearing, M. D. 2012. Experience matters: Prior exposure to plant toxins enhances diversity of gut microbes in herbivores. Ecol. Lett. 15:1008-1015.

Kohl, K. D., Weiss, R. B., Dale, C., and Dearing, M. D. 2011. Diversity and novelty of the gut microbial community of an herbivorous rodent (Neotoma bryanti). Symbiosis 54:47-54.
Kong, D. X., JiAng, Y. Y., and ZhANG, H. Y. 2010. Marine natural products as sources of novel scaffolds: Achievement and concern. Drug Discov. Today 15:884-886.

Kool, K. M. 1992. Food selection by the silver leaf monkey, Trachypithecus-Auratus-Sondaicus, in relation to plant chemistry. Oecologia 90:527-533.

Langille, M. G. I., Laird, M. R., Hsiao, W. W. L., ChiU, T. A., EISEN, J. A., and BRINKMAN, F. S. L. 2012. MicrobeDB: A locally maintainable database of microbial genomic sequences. Bioinformatics 28:1947-1948.

LAVIN, S. R. and KARASOV, W. H. 2008. Allometry of paracellular absorption in birds. Physiol. Biochem. Zool. 81:551-560.

LAWLER, I. R., Foley, W. J., PASS, G. J., and Eschler, B. M. 1998. Administration of a $5 \mathrm{HT}(3)$ receptor antagonist increases the intake of diets containing eucalyptus secondary metabolites by marsupials. J. Comp. Physiol. B, Biochem. Syst. Environ. Physiol. 168:611-618

LaWler, I. R., Stapley, J., Foley, W. J., and Eschler, B. M. 1999. Ecological example of conditioned flavor aversion in plantherbivore interactions: Effect of terpenes of Eucalyptus leaves on feeding by common ringtail and brushtail possums. J. Chem. Ecol. 25:401-415.

LAWler, I. R., ARAgONES, L., Berding, N., MARSh, H., and Foley, W. 2006. Near-infrared reflectance spectroscopy is a rapid, cost-effective predictor of seagrass nutrients. J. Chem. Ecol. 32:1353-1365.

Ley, R. E., Peterson, D. A., and Gordon, J. I. 2006. Ecological and evolutionary forces shaping microbial diversity in the human intestine. Cell 124:837-848.

Ley, R. E., Hamady, M., Lozupone, C., Turnbaugh, P. J., Ramey, R. R., BIRCHER, J. S., et al. 2008. Evolution of mammals and their gut microbes. Science 320:1647-1651.

Liang, X. F., LI, G. G., He, S., and HuANG, Y. 2007. Transcriptional responses of alpha- and rho-class glutathione S-Transferase genes in the liver of three freshwater fishes intraperitoneally injected with microcystin-LR: Relationship of inducible expression and tolerance. J. Biochem. Mol. Toxicol. 21:289-298.

LINDROTH, R. L. 2010. Impacts of elevated atmospheric $\mathrm{CO}(2)$ and $\mathrm{O}(3)$ on forests: Phytochemistry, trophic interactions, and ecosystem dynamics. J. Chem. Ecol. 36:2-21.

Lokvam, J., Brenes-Arguedas, T., Lee, J. S., Coley, P. D., and KURSAR, T. A. 2006. Allelochemic function for a primary metabolite: The case of L-tyrosine hyper-production in Inga umbellifera (Fabaceae). Am. J. Bot. 93:1109-1115.

Magnanou, E., MalenKe, J. R., and DeARING, M. D. 2009. Expression of biotransformation genes in woodrat (Neotoma) herbivores on novel and ancestral diets: Identification of candidate genes responsible for dietary shifts. Mol. Ecol. 18:2401-2414.

MAJAK, W. 1992. Mammalian metabolism of toxic glycosides from plants. J. Toxicol. Toxin. Rev. 11:1-40.

Malenke, J. R., Magnanou, E., and Dearing, M. D. 2011. Cytochrome $\mathrm{P} 450$ 2B diversity in a wild rodent herbivore, the desert woodrat (Neotoma lepida). Integr. Comp. Biol. 51: E85-E85.

Mangione, A. M., Dearing, M. D., and Karasov, W. H. 2004. Creosote bush (Larrea tridentata) resin increases water demands and reduces energy availability in desert woodrats (Neotoma lepida). J. Chem. Ecol. 30:1409-1429.

MARgulies, E. H. and BIRNEY, E. 2008. Approaches to comparative sequence analysis: Towards a functional view of vertebrate genomes. Nat. Rev. Genet. 9:303-313.

Marsh, K. J., Wallis, I. R., and Foley, W. J. 2005. Detoxification rates constrain feeding in common brushtail possums (Trichosurus vulpecula). Ecology 86:2946-2954.

MARSH, K. J., WAllis, I. R., ANDREW, R. L., and Foley, W. J. $2006 a$. The detoxification limitation hypothesis: Where did it come from and where is it going? J. Chem. Ecol. 32:1247-1266. 
Marsh, K. J., Wallis, I. R., McLean, S., Sorensen, J. S., and FOLEY, W. J. 2006b. Conflicting demands on detoxification pathways influence how common brushtail possums choose their diets. Ecology 87:2103-2112.

Marsh, K. J., Wallis, I. R., and Foley, W. J. 2007. Behavioural contributions to the regulated intake of plant secondary metabolites in koalas. Oecologia 154:283-290.

MARTIN-CreuZBURG, D. and VON ElERT, E. 2009. Good food versus bad food: The role of sterols and polyunsaturated fatty acids in determining growth and reproduction of Daphnia magna. Aquat. Ecol. 43:943-950.

MARTins, J. C. and VASCONCELOS, V. M. 2009. Microcystin dynamics in aquatic organisms. J. Toxicol. Environ. Health B Crit. Rev. 12:65-82.

Masahira, H., Oshima, K., Kim, S., KurOKaWa, K., ToH, H., and TAYLOR, T. 2009. Metagenomics and genomics decoding human gut microbiomes. Genes Genet. Syst. 84:479-479.

Matteotti, C., Thonart, P., Francis, F., Haubruge, E., Destain, J., BRASSEUR, C., et al. 2011. New glucosidase activities identified by functional screening of a genomic DNA library from the gut microbiota of the termite Reticulitermes santonensis. Microbiol. Res. 166:629-642.

Mayntz, D., Nielsen, V. H., Sorensen, A., Toft, S., Raubenheimer, D., HeJlesen, C., et al. 2009. Balancing of protein and lipid intake by a mammalian carnivore, the mink, mustela vison. Anim. Behav. 77:349-355.

MCLEAN, S. and DunCAN, A. J. 2006. Pharmacological perspectives on the detoxification of plant secondary metabolites: Implications for ingestive behavior of herbivores. J. Chem. Ecol. 32:1213-1228.

Mclean, S., Brandon, S., Davies, N. W., Foley, W. J., AND MulleR, H. K. 2004. Jensenone: Biological reactivity of a marsupial antifeedant from Eucalyptus. J. Chem. Ecol. 30:19-36.

Mclean, S., Boyle, R. R., BRandon, S., Davies, N. W., and SORENSEN, J. S. 2007. Pharmacokinetics of 1,8-cineole, a dietary toxin, in the brushtail possum (Trichosurus vulpecula): Significance for feeding. Xenobiotica 37:903-922.

Mclean, S., Richards, S. M., Cover, S. L., Brandon, S., Davies, N. W., BRYANT, J. P., et al. 2009. Papyriferic acid, an antifeedant triterpene from birch trees, inhibits succinate dehydrogenase from liver mitochondria. J. Chem. Ecol. 35:1252-1261.

McLister, J. D., Sorensen, J. S., and DeAring, M. D. 2004. Effects of consumption of juniper (Juniperus monosperma) on cost of thermoregulation in the woodrats Neotoma albigula and Neotoma stephensi at different acclimation temperatures. Physiol. Biochem. Zool. 77:305-312.

McWhorter, T. J., CAVIEDES-Vidal, E., and Karasov, W. H. 2009. The integration of digestion and osmoregulation in the avian gut. Biol. Rev. 84:533-565.

Miller, G. A., Clissold, F. J., Mayntz, D., and Simpson, S. J. 2009. Speed over efficiency: Locusts select body temperatures that favour growth rate over efficient nutrient utilization. Proc. Biol. Sci. 276:3581-3589.

Min, B. R., BARry, T. N., ATtwood, G. T., and MCNABB, W. C. 2003. The effect of condensed tannins on the nutrition and health of ruminants fed fresh temperate forages: A review. Anim. Feed. Sci. Technol. 106:3-19.

Mondal, S., RoY, T., SEN, S. K., and RaY, A. K. 2008. Distribution of enzyme-producing bacteria in the digestive tracts of some freshwater fish. Acta Ichtyol. Pisc. 38:1-8.

Moore, B. D. and Foley, W. J. 2005. Tree use by koalas in a chemically complex landscape. Nature 435:488-490.

Moore, B. D., LaWler, I. R., Wallis, I. R., Beale, C. M., and FOLEY, W. J. 2010. Palatability mapping: A koala's eye view of spatial variation in habitat quality. Ecology 91:3165-3176.

Mountfort, D. O., CAMPBell, J., and Clements, K. D. 2002. Hindgut fermentation in three species of marine herbivorous fish. Appl. Environ. Microbiol. 68:1374-1380.
Nersesian, C. L., Banks, P. B., and McArthur, C. 2011. Titrating the cost of plant toxins against predators: Determining the tipping point for foraging herbivores. J. Anim. Ecol. 80:753-760.

Nersesian, C. L., Banks, P. B., Simpson, S. J., and McArthur, C. 2012. Mixing nutrients mitigates the intake constraints of a plant toxin in a generalist herbivore. Behav. Ecol. 23:879-888.

Newman, R. M., KerfoOt, W. C., and Hanscom, Z. 1996. Watercress allelochemical defends high-nitrogen foliage against consumption: Effects on freshwater invertebrate herbivores. Ecology 77:23122323.

OPITZ, S. E. W. and Muller, C. 2009. Plant chemistry and insect sequestration. Chemoecology 19:117-154.

PALO, R. and RoBbins, C. 1991. Plant Defences Against Mammalian Herbivory. CRC Press, Inc, Boca Raton, FL.

Paul, N. A., DE Nys, R., SteinBerg, P. D. 2006. Seaweed-herbivore interactions at a small scale: direct tests of feeding deterrence by filamentous algae. Marine Ecology-Progress Series. 323:1-9.

PaUl, V. J. and VANalstyne, K. L. 1992. Activation of chemical defenses in the tropical green-algae Halimeda spp. J. Exp. Mar. Biol. Ecol. 160:191-203.

Pennings, S. C. and PAUL, V. J. 1993. Secondary chemistry does not limit dietary range of the specialist sea hare Stylocheilum ongicauda. J. Exp. Mar. Biol. Ecol. 174:97-113.

Perez, T., Balcazar, J. L., Ruiz-Zarzuela, I., Halaihel, N., VENDRELL, D., DE BLAS, I., et al. 2010. Host-microbiota interactions within the fish intestinal ecosystem. Mucosal Immunol. 3:355-360.

Peter, H. and Sommaruga, R. 2008. An evaluation of methods to study the gut bacterial community composition of freshwater zooplankton. J. Plankton Res. 30:997-1006.

Petschenka, G., Offe, J. K., and Dobler, S. 2012. Physiological screening for target site insensitivity and localization of $\mathrm{Na}+\mathrm{K}+$ -ATPase in cardenolide-adapted Lepidoptera. J. Insect Physiol. 58:607-612.

Poore, A. G. B., Hill, N. A., and SotKA, E. E. 2008. Phylogenetic and geographic variation in host breadth and composition by herbivorous amphipods in the family Ampithoidae. Evolution 62:21-38.

Porras-Alfaro, A. and Bayman, P. 2011. Hidden fungi, emergent properties: Endophytes and microbiomes, pp. 291-315, in N. K. VanAlfen, G. Bruening, and J. E. Leach (eds.), Annual Review of Phytopathology, vol 49. Annual Reviews, Palo Alto.

Provenza, F. D., Villalba, J. J., Cheney, C. D., and Werner, S. J. 1998. Self-organization of foraging behaviour: From simplicity to complexity without goals. Nutr. Res. Rev. 11:199-222.

Provenza, F. D., Villalba, J. J., DziBa, L. E., ATwood, S. B., and BANNER, R. E. 2003. Linking herbivore experience, varied diets, and plant biochemical diversity. Small Rumin. Res. 49:257-274.

RAUBENHEIMER, D. and Simpson, S. J. 1997. Integrative models of nutrient balancing: Application to insects and vertebrates. Nutr. Res. Rev. 10:151-179.

Raubenheimer, D. and Simpson, S. J. 2009. Nutritional pharmecology: Doses, nutrients, toxins, and medicines. Integr. Comp. Biol. 49:329-337.

RAUBENHEIMER, D., Simpson, S. J., and MAYNTZ, D. 2009. Nutrition, ecology and nutritional ecology: Toward an integrated framework. Funct. Ecol. 23:4-16.

Rewitz, K. F., StyrishaVe, B., LOBNER-Olesen, A., and ANDERSEN, O. 2006. Marine invertebrate cytochrome P450: Emerging insights from vertebrate and insect analogies. Comp. Biochem. Physiol. C Pharmacol. Toxicol. Endocrinol. 143:363-381.

Reynaud, S., Raveton, M., and Ravanel, P. 2008. Interactions between immune and biotransformation systems in fish: A review. Aquat. Toxicol. 87:139-145.

Richardson, K. L., Gold-Bouchot, G., and SchlenK, D. 2009. The characterization of cytosolic glutathione transferase from four species of sea turtles: Loggerhead (Caretta caretta), green 
(Chelonia mydas), olive ridley (Lepidochelys olivacea), and hawksbill (Eretmochelys imbricata). Comp. Biochem. Physiol. C Pharmacol. Toxicol. Endocrinol. 150:279-284.

Rincon, M. T., Allison, M. J., Michelangeli, F., De Sanctis, Y., and Dominguez-Bello, M. G. 1998. Anaerobic degradation of mimosine-derived hydroxypyridines by cell free extracts of the rumen bacterium Synergistes jonesii. FEMS Microbiol. Immunol. 27:127-132.

Rothman, J. M., Raubenheimer, D., and Chapman, C. A. 2011. Nutritional geometry: Gorillas prioritize non-protein energy while consuming surplus protein. Biol. Lett. 7:847-849.

SCRIBER, J. M. and SlanSKY, F. 1981. The nutritional ecology of immature insects. Annu. Rev. Entomol. 26:183-211.

Shawahna, R., Uchida, Y., Decleves, X., Ohtsuki, S., Yousif, S., DAUCHY, S., et al. 2011. Transcriptomic and quantitative proteomic analysis of transporters and drug metabolizing enzymes in freshly isolated human brain microvessels. Mol. Pharm. 8:13321341.

SHIMADA, T. 2006. Salivary proteins as a defense against dietary tannins. J. Chem. Ecol. 32:1149-1163.

Shipley, L. A., Forbey, J. S., and Moore, B. D. 2009. Revisiting the dietary niche: When is a mammalian herbivore a specialist? Integr. Comp. Biol. 49:274-290.

Simpson, S. J. and RAUBENHEIMER, D. 2001. The geometric analysis of nutrient-allelochemical interactions: A case study using locusts. Ecology 82:422-439.

Simpson, S. J., Raubenheimer, D., Charleston, M. A., Clissold, F. J., et al. 2010. Modelling nutritional interactions: From individuals to communities. Trends Ecol. Evol. 25:53-60.

SKOPEC, M. M., GREEN, A. K., and KARASOV, W. H. 2010. Flavonoids have differential effects on glucose absorption in rats (Rattus norvegicus) and american robins (Turdis migratorius). J. Chem. Ecol. 36:236-243.

SLANSKY, F. 1992. Allelochemical-nutrient interactions in herbivore nutritional ecology, pp. 135-175, in G. Rosenthal and M. Berenbaum (eds.), Herbivores: Their Interactions with Secondary Plant Metabolites. Academic, San Diego.

Smital, T., Luckenbach, T., Sauerborn, R., Hamdoun, A. A., VEGA, R. L., and EPEL, D. 2004. Emerging contaminants - pesticides, PPCPs, microbial degradation products and natural substances as inhibitors of multixenobiotic defense in aquatic organisms. Mutat. Res. 552:101-117.

Sorensen, J. S. and DeARING, M. D. 2006. Efflux transporters as a novel herbivore countermechanism to plant chemical defenses. $J$. Chem. Ecol. 32:1181-1196.

Sorensen, J. S., Turnbull, C. A., and Dearing, M. D. 2004. A specialist herbivore (Neotoma stephensi) absorbs fewer plant toxins than a generalist (Neotoma albigula). Physiol. Biochem. Zool. 77:139-148.

Sorensen, J. S., Heward, E., and Dearing, M. D. 2005a. Plant secondary metabolites alter the feeding patterns of a mammalian herbivore (Neotoma lepida). Oecologia 146:415-422.

Sorensen, J. S., McLister, J. D., and DeAring, M. D. 2005b. Novel plant secondary metabolites impact dietary specialists more than generalists (Neotoma spp.). Ecology 86:140-154.

Sorensen, J. S., McLister, J. D., and Dearing, M. D. 2005c. Plant secondary metabolites compromise the energy budgets of specialist and generalist mammalian herbivores. Ecology 86:125-139.

Sorensen, J. S., Skopec, M. M., and Dearing, M. D. 2006. Application of pharmacological approaches to plant-mammal interactions. J. Chem. Ecol. 32:1229-1246.

Sotka, E. E., Forbey, J., Horn, M., Poore, A. G. B., RAubenheimer, D., and Whalen, K. E. 2009. The emerging role of pharmacology in understanding consumer-prey interactions in marine and freshwater systems. Integr. Comp. Biol. 49:291-313.
Stapley, J., Foley, W. J., CunNingham, R., and Eschler, B. 2000. How well can common brushtail possums regulate their intake of Eucalyptus toxins? J. Comp. Physiol. B, Biochem. Syst. Environ. Physiol. 170:211-218.

Stevens, C. E. and Hume, I. D. 1998. Contributions of microbes in vertebrate gastrointestinal tract to production and conservation of nutrients. Physiol. Rev. 78:393-427.

Stolter, C., Julkunen-TittTo, R., and Ganzhorn, J. U. 2006. Application of near infrared reflectance spectroscopy (NIRS) to assess some properties of a sub-arctic ecosystem. Basic Appl. Ecol. 7:167-187.

Sullam, K. E., Essinger, S. D., Lozupone, C. A., O'Connor, M. P., Rosen, G. L., KNIGHT, R., et al. 2012. Environmental and ecological factors that shape the gut bacterial communities of fish: A meta-analysis. Mol. Ecol. 21:3363-3378.

TARgEtT, N. M. and ARnOLD, T. M. 2001. Effects of secondary metabolites on digestion in marine herbivores, pp 391-412, in C. D. Amsler (ed.), Marine Chemical Ecology. CRC Press.

ThiYAgarajan, V. and QIAN, P. Y. 2008. Proteomic analysis of larvae during development, attachment, and metamorphosis in the fouling barnacle, Balanus amphitrite. Proteomics 8:3164-3172.

Torregrossa, A. M. and DeAring, M. D. 2009. Nutritional toxicology of mammals: Regulated intake of plant secondary compounds. Funct. Ecol. 23:48-56.

Torregrossa, A. M., Azzara, A. V., and Dearing, M. D. 2011. Differential regulation of plant secondary compounds by herbivorous rodents. Funct. Ecol. 25:1232-1240.

Torregrossa, A. M., Azzara, A. V., and Dearing, M. D. 2012. Testing the diet-breadth trade-off hypothesis: Differential regulation of novel plant secondary compounds by a specialist and a generalist herbivore. Oecologia 168:711-718.

Turtola, S., Rousi, M., Pusenius, J., Yamaji, K., Heiska, S., TirkKonen, V., et al. 2005. Clone-specific responses in leaf phenolics of willows exposed to enhanced UVB radiation and DROUGHT STRESS. GLOBAL CHANGE BIOL. 11:1655-1663.

van Alstyne, K. L., Pelletreau, K. N., and Kirby, A. 2009. Nutritional preferences override chemical defenses in determining food choice by a generalist herbivore, Littorina sitkana. J. Exp. Mar. Biol. Ecol. 379:85-91.

VERMEIJ, G. J. and LinDBERG, D. R. 2000. Delayed herbivory and the assembly of marine benthic ecosystems. Paleobiology 26:419 430.

WALENCIAK, O., ZWISLER, W., and GROSS, E. 2002. Influence of Myriophyllum spicatum-derived tannins on gut microbiota of its herbivore Acentria ephemerella. J. Chem. Ecol. 28:20452056.

WeINSTOCK, G. M. 2012. Genomic approaches to studying the human microbiota. Nature 489:250-256.

Wen, Z. M., BerenBaum, M. R., and SchUler, M. A. 2006. Inhibition of CYP6B1-mediated detoxification of xanthotoxin by plant allelochemicals in the black swallowtail (Papilio polyxenes). $J$. Chem. Ecol. 32:507-522.

Whalen, K. E., Morin, D., Lin, C. Y., Tueerdema, R. S., Goldstone, J. V., and Hahn, M. E. 2008. Proteomic identification, cDNA cloning and enzymatic activity of glutathione Stransferases from the generalist marine gastropod, Cyphoma gibbosum. Arch. Biochem. Biophys. 478:7-17.

Whalen, K. E., SotKa, E. E., Goldstone, J. V., and Hahn, M. E. 2010. The role of multixenobiotic transporters in predatory marine molluscs as counter-defense mechanisms against dietary allelochemicals. Comp. Biochem. Physiol. C Toxicol. Pharmacol. 152:288-300.

Whiteman, N. K., Groen, S. C., Chevasco, D., Bear, A., BeCKWith, N., Gregory, T. R., et al. 2011. Mining the plantherbivore interface with a leafmining Drosophila of Arabidopsis. Mol. Ecol. 20:995-1014. 
Wiggins, N. L., McArthur, C., Mclean, S., and Boyle, R. 2003. Effects of two plant secondary metabolites, cineole and gallic acid, on nightly feeding patterns of the common brushtail possum. J. Chem. Ecol. 29:1447-1464.

Wiggins, N. L., Marsh, K. J., Wallis, I. R., Foley, W. J., and MCARThur, C. 2006a. Sideroxylonal in Eucalyptus foliage influences foraging behaviour of an arboreal folivore. Oecologia 147:272279.

Wiggins, N. L., McArthur, C., and Davies, N. W. 2006b. Diet switching in a generalist mammalian folivore: Fundamental to maximising intake. Oecologia 147:650-657.

Wright, G. A., Simpson, S. J., Raubenheimer, D., and Stevenson, P. C. 2003. The feeding behavior of the weevil, Exophthalmus jekelianus, with respect to the nutrients and allelochemicals in host plant leaves. Oikos 100:172-184.

WU, J. Q. and BALDWIN, I. T. 2009. Herbivory-induced signalling in plants: Perception and action. Plant Cell Environ. 32:1161-1174.
YAmamoto, K., QI, W. M., YoKoO, Y., Miyata, H., Udayanga, K. G. S., KAWANO, J., et al. 2009. Histoplanimetrical study on the spatial relationship of distribution of indigenous bacteria with mucosal lymphatic follicles in alimentary tract of rat. J. Vet. Med. Sci. 71:621-630.

Yeager, C. P., Silver, S. C., and Dierenfeld, E. S. 1997. Mineral and phytochemical influences on foliage selection by the proboscis monkey (Nasalis larvatus). Am. J. Primatol. 41:117-128.

Zangerl, A. R., Liao, L. H., Jogesh, T., and Berenbaum, M. R. 2012. Aliphatic esters as targets of esterase activity in the Parsnip Webworm (Depressaria pastinacella). J. Chem. Ecol. 38:188194.

Zhou, S. F., Wang, L. L., Di, Y. M., Xue, C. C., Duan, W., Li, C. G., et al. 2008. Substrates and inhibitors of human multidrug resistance associated proteins and the implications in drug development. Curr. Med. Chem. 15:1981-2039. 